\section{Low-temperature Storage for Quality Preservation and Growth Suppression of Broccoli Plantlets Cultured in Vitro}

\author{
Chieri Kubota ${ }^{1}$ and Toyoki Kozai ${ }^{2}$ \\ Faculty of Horticulture, Chiba University, Matsudo, Chiba 271, Japan
}

Additional index words. Brassica oleracea L., environmental control, growth control

\begin{abstract}
Broccoli (Brassica oleracea L. Botrytis Group 'Ryokurei') plantlets, cultured photoautotrophically (without sugar in the medium) in vitro for 3 weeks at $23 \mathrm{C}$ and 160 $\mu \mathrm{mol} \cdot \mathrm{m}^{-2} \cdot \mathrm{s}^{-1}$ photosynthetic photon flux (PPF), were stored for 6 weeks at 5,10 , or $15 \mathrm{C}$ under 0 (darkness) or $2 \mu \mathrm{mol} \cdot \mathrm{m}^{-2} \cdot \mathrm{s}^{-1}$ PPF (continuous lighting) supplied by fluorescent lamps (white light). Dry weight of the plantlets stored for 6 weeks at 5 or $10 \mathrm{C}$ in light was not significantly different from that of the plantlets before storage. Dry weight of the plantlets decreased as temperature increased and was maintained at higher levels in light than in darkness. Chlorophyll concentrations of the plantlets were higher at the lower temperatures. Chlorophyll fluorescence kinetics indicated higher activities of chlorophyll of the plantlets stored in light than in darkness. Lighting at as low as $2 \mu \mathrm{mol} \cdot \mathrm{m}^{-2} \cdot \mathrm{s}^{-1} \mathbf{P P F}$ was important to preserve photosynthetic and regrowth abilities and dry weight of the plantlets during low-temperature storage.
\end{abstract}

In commercial micropropagation, plantlets in vitro sometimes reach a desirable size for transplanting or shipping before the labor for transplanting or the greenhouse space for acclimatization is available, or before the market or customers are ready to accept them. Under such circumstances, the plantlets need to be stored without loss of quality and dry weight. With seasonal crops, such as vegetables and flowers, production peaks can create a serious problem. Transfer schedules and production management should be arranged with consideration for successful commercial production.

Low-temperature storage is commonly used for harvested vegetables and fruits and could have potential as a holding method for micropropagated plantlets. Intensive studies have been done for long-term, low-temperature storage of micropropagated propagules to achieve genetic conservation (e.g., Bessembinder et al., 1993). However, to our knowledge, no data exist on short-term storage (for $<6$ months) of micropropagated plantlets. Effects of environmental factors affecting quality degradation of micropropagated

Received for publication 20 Oct. 1993. Accepted for publication 23 Apr. 1994. The mention of commercial products, their source, or their use in connection with the research reported herein is not to be construed as either an actual or implied endorsement of said products. We thank Royal D. Heins, Michigan State Univ., and Irwin Chu, Twyford International, Calif., for their helpful advice. Appreciation is also extended to Roy E. Young, Clemson Univ., S.C., for critical reading. The cost of publishing this paper was defrayed in part by the payment of page charges. Under postal regulations, this paper therefore must be hereby marked advertisement solely to indicate this fact.

${ }^{1}$ Current address: Dept. of Horticulture, Clemson Univ., Clemson, SC 29634-0375.

${ }^{2}$ Professor. plantlets during storage have not been reported.

The objective of this study was to determine the storage environmental conditions that result in minimal damage to photosynthetic and regrowth abilities and minimum loss of dry weight of the plantlets.

\section{Materials and Methods}

Plant material and culture conditions. 'Ryokurei' broccoli seedlings were used as model plantlets. The seeds were surface-disinfected with $1 \%$ sodium hypochlorite solution for $10 \mathrm{~min}$ before culture initiation, and the plantlets were cultured photoautotrophically for 3 weeks under conditions shown in Table 1. Four plantlets were cultured in each of the vessels: six seeds were placed on the medium, and two plantlets were removed when the cotyledonary leaves were fully expanded (3 days after culture initiation). Two membrane filter disks (Milli-Seal, Millipore K.K., Tokyo: pore size $0.5 \mu \mathrm{m}$ ) were placed so that they would cover a pair of holes $(10 \mathrm{~mm}$ in diameter, $50 \mathrm{~mm}$ above the medium surface level) on opposite sides of the vessel. The number of air exchanges of the vessels (hourly ventilation rate divided by vessel air volume) was estimated according to Kozai et al. (1986).

Storage conditions and treatments. Three weeks after initiation of culture, vessels were placed under one of six storage conditions: light $\left[2 \pm 0.5 \mu \mathrm{mol} \cdot \mathrm{m}^{-2} \cdot \mathrm{s}^{-1}\right.$ photosynthetic photon flux (PPF)] or darkness and air temperatures $5.0 \pm 1.0 \mathrm{C}, 10.0 \pm 0.5 \mathrm{C}$, or $15.0 \pm 0.5 \mathrm{C}$; nine additional vessels were left in the culture room without storage, as the unstored control.

Before storage, the membrane filters on the vessel were covered with plastic tape to avoid excessive water loss during storage. The vessels stored in darkness were covered with aluminum foil to exclude all light. The number of air exchanges of the vessel during storage was estimated to be $<0.1$ per hour for the vessels either in light or darkness. The light source in storage was fluorescent lamps (white light) that provided a $24-\mathrm{h}$ (continuous) photoperiod.

Measurements. After 3 and 6 weeks of storage, four vessels were selected randomly from each of the treatments for destructive measurements of fresh and dry weight, number of leaves, leaf area, and stem length of the plantlets. Chlorophyll fluorescence intensity and total chlorophyll (chlorophyll a plus chlorophyll b) concentration were measured on two plantlets in each of the treatments. Chlorophyll fluorescence intensity was measured at two wavelengths (695 and $730 \mathrm{~nm}$ ) on two leaves each of the plantlets using a modulated fluorescence measurement system (MFMSII-T; Hansatech Co., Norfolk, England). A parameter $f_{\max }: f_{0}$, which is the ratio of maximum fluorescence $f_{\max }$ to ground fluorescence $\mathrm{f}_{0}$ (Lichtenthaler, 1988), was calculated from the chlorophyll fluorescence induction kinetics. Plantlets were kept in darkness at room temperature for $2 \mathrm{~h}$ before measuring chlorophyll fluorescence intensity. Chlorophyll concentration was estimated according to Arnon (1949). Fresh and dry weights, number of leaves, leaf area, stem length, chlorophyll contents, chlorophyll fluorescence intensity, and net photosynthetic rate were also measured before storage. Plantlet growth measurements were also made with the plantlets left for 2,3 , and 6 weeks in the culture room without storage.

Carbon dioxide and ethylene concentrations inside and outside the vessels were measured at multiple-day intervals during storage. The measurements of $\mathrm{CO}_{2}$ and ethylene were made quantitatively above $1 \mu \mathrm{mol} \cdot \mathrm{mol}^{-1}$ using a gas chromatograph (GC12A; Shimazu Co., Kyoto, Japan). The chromatograph was calibrated before every set of measurements. Air temperatures were monitored throughout storage period using 0.1-mm copper-constantan thermocouples set in each storage.

After 3 and 6 weeks of storage, three vessels in each of the treatments were returned to the culture room. Except for 1 day for acclimatization under $50 \mu \mathrm{mol} \cdot \mathrm{m}^{-2} \cdot \mathrm{s}^{-1} \mathrm{PPF}$ and low air exchanges $(<0.1$ per hour $)$, the plantlets were subsequently cultured for 2 weeks under the

Table 1. Culture conditions of broccoli plantlets in vitro.

\footnotetext{
Medium

Basal component: Murashige and Skoog (1962) Sugar: None

Gelling agent: $8 \mathrm{~g}$ agar/liter

Growth regulator: None

$\mathrm{pH}$ : 5.8 before autoclaving

Volume: $50 \mathrm{ml} / \mathrm{vessel}$

Culture vessels: Box-type polycarbonate vessels Air volume: $370 \mathrm{ml}$

Number of air exchanges: $3.6 / \mathrm{h}$

Culture room

Air temperature: $23 \pm 2 \mathrm{C}$

Photosynthetic photon flux: $160 \mu \mathrm{mol} \cdot \mathrm{m}^{-2} \cdot \mathrm{s}^{-1}$ on the empty culture shelf

Light source: Cool-white fluorescent lamps Photoperiod: 16 h/day
} 
same culture conditions as before storage. Two days after starting subsequent culture, $\mathrm{CO}_{2}$ concentrations inside and outside the vessel were measured 1 to $2 \mathrm{~h}$ before the end of photoperiod, when the $\mathrm{CO}_{2}$ concentrations were stable over time. According to Fujiwara et al. (1987), net photosynthetic rate of the plantlets in the vessel was calculated from the difference in $\mathrm{CO}_{2}$ concentrations between inside and outside the vessel, number of air exchanges of the vessel, and air volume of the vessel. The growth data obtained from the plantlets left for 2 weeks without storage in the culture room were compared with those obtained from the plantlets cultured for 2 weeks subsequent to 3 or 6 weeks of storage.

There were 14 vessels per treatment, which gave 56 plantlets per treatment. Four vessels each were harvested after 3 and 6 weeks of storage, and three vessels each after 2 weeks of subsequent culture. Each vessel with four plantlets was considered as a replication. The statistical differences between before and after storage and between with and without storage were determined by $t$ test.

\section{Results and Discussion}

Plantlet growth. Plantlets stored for 3 weeks at 5 or $10 \mathrm{C}$ in light and at $5 \mathrm{C}$ in darkness and for 6 weeks at 5 or $10 \mathrm{C}$ in light appeared vigorous and similar to the plantlets before storage. Dry weights of the plantlets stored for 3 or 6 weeks at 5 or $10 \mathrm{C}$ in light were not significantly different from those before storage (Table 2). After 3 and 6 weeks of storage, dry weights of the plantlets decreased as temperature increased, but remained higher in light than in darkness. The dry weights of the plantlets left in the culture room for 3 or 6 weeks without storage were, respectively, 2.7 and 3.8 times that of the plantlets before storage.

During 6 weeks of storage, stem length, number of leaves, and leaf area of the plantlets did not increase regardless of the storage treatment (data not shown). Stem length of the plantlets left for 6 weeks without storage was 1.7 times that before storage. Shoot tops of the plantlets reached the lid of the vessel, causing stem distortion and leaf yellowing.

Chlorophyll concentration and chlorophyll fluorescence ratio $f_{\max }: f_{0}$. Chlorophyll concentrations after 3 and 6 weeks of storage were significantly lower than those before storage, regardless of storage treatment (Table 2); the concentrations also were higher in light than in darkness at 5 and $15 \mathrm{C}$ after 3 weeks of storage. Chlorophyll concentration decreased dramatically in plantlets stored 6 weeks at $15 \mathrm{C}$ in light.

The percentage of yellowing leaves increased as temperatures increased. All the leaves of the plantlets stored for 3 weeks at 10 or $15 \mathrm{C}$ in darkness had softened, as did those stored for 6 weeks at 5, 10, or 15C in darkness and some at $15 \mathrm{C}$ in light.

The chlorophyll fluorescence ratios $\mathrm{f}_{\max }: \mathrm{f}_{0}$ at 695 and $730 \mathrm{~nm}$ were highest for plantlets stored at $5 \mathrm{C}$ in light. In decreasing order of values, the ratios ranked as follows: $10 \mathrm{C}$ in light, $15 \mathrm{C}$ in light, $5 \mathrm{C}$ in darkness, $10 \mathrm{C}$ in darkness after 3 and 6 weeks of storage. Chlorophyll fluorescence intensities were not measured for the plantlets stored at $15 \mathrm{C}$ in darkness because the plantlets were too soft to be set properly in the measurement system.

The plantlets stored in darkness had a relatively low $f_{\max }: f_{0}$ ratio after 3 and 6 weeks of storage, even though the chlorophyll concentrations were similar to those of plantlets stored in light (Table 2). This result suggests that the chlorophyll remaining in the leaves of the plantlets stored in darkness lost its ability to operate the processes of photosynthesis. A decrease of $f_{\max }: f_{0}$ has been reported when the reaction-center chlorophyll of photosystem II was destroyed (Lichtenthaler, 1988).

Net photosynthetic rate under culture conditions. Net photosynthetic rates $\left(\mathrm{P}_{\mathrm{d}}\right)$ of the plantlets measured after return to culture conditions were similar to those before storage when plantlets were stored for 3 and 6 weeks at 5 or $10 \mathrm{C}$ in light or for 3 weeks at $15 \mathrm{C}$ in light (Table 3). The $\mathrm{CO}_{2}$ concentrations inside those vessels were more than $200 \mu \mathrm{mol} \cdot \mathrm{mol}^{-1}$ lower than the ambient $\mathrm{CO}_{2}$ concentration. It would be desirable to obtain photosynthetic response curves under various $\mathrm{CO}_{2}$ concentrations and PPF to discern the photosynthetic capacity of stored plantlets.

The $P_{d}$ values were negative after plantlets had been stored for 3 weeks at 10 or $15 \mathrm{C}$ in darkness or for 6 weeks at $15 \mathrm{C}$ in light and at 5,10 , or $15 \mathrm{C}$ in darkness. Thus, the plantlets had significantly decreased or lost their photosynthetic ability during storage, which is in agreement with low $\mathrm{f}_{\max }: \mathrm{f}_{0}$.

Carbon dioxide concentrations inside the vessel during storage. For the first 3 weeks in storage, $\mathrm{CO}_{2}$ concentration inside the vessel was highest at $15 \mathrm{C}$ in darkness, followed in decreasing order by $10 \mathrm{C}$ in darkness, $5 \mathrm{C}$ in darkness, $15 \mathrm{C}$ in light, $10 \mathrm{C}$ in light, and $5 \mathrm{C}$ in

Table 2. Dry weight per plantlet, leaf chlorophyll concentration (dry weight basis), and chlorophyll fluorescence ratio $\mathrm{f}_{\max }: \mathrm{f}_{0}$ of broccoli plantlets before and after 3 or 6 weeks of storage. Means \pm standard deviations are shown.

\begin{tabular}{|c|c|c|c|c|c|}
\hline \multicolumn{2}{|c|}{ Treatments } & \multirow{2}{*}{$\begin{array}{c}\text { Dry wt } \\
\text { (mg/plantlet) }\end{array}$} & \multirow{2}{*}{$\begin{array}{c}\text { Chlorophyll } \\
\text { concn } \\
\left(\mathrm{mg} \cdot \mathrm{g}^{-1}\right)\end{array}$} & \multicolumn{2}{|c|}{$\mathrm{f}_{\max }: \mathrm{f}_{0}$} \\
\hline Temp $\left({ }^{\circ} \mathrm{C}\right)$ & Light & & & at $695 \mathrm{~nm}$ & at $730 \mathrm{~nm}$ \\
\hline \multicolumn{6}{|c|}{ Before storage } \\
\hline & & $39 \pm 0.7$ & $20 \pm 0.9$ & $5.7 \pm 0.42$ & $3.7 \pm 0.12$ \\
\hline \multicolumn{6}{|c|}{ After 3 weeks of storage } \\
\hline 5 & + & $39 \pm 2.7^{\mathrm{Ns}}$ & $15 \pm 0.8^{* *}$ & $5.6 \pm 0.39^{\mathrm{Ns}}$ & $5.5 \pm 0.03^{* *}$ \\
\hline 10 & + & $36 \pm 1.8^{\mathrm{Ns}}$ & $10 \pm 1.0^{* * *}$ & $4.0 \pm 0.24^{* *}$ & $3.8 \pm 0.14^{\mathrm{Ns}}$ \\
\hline 15 & + & $29 \pm 1.2^{* * *}$ & $11 \pm 1.0^{* * *}$ & $2.1 \pm 0.10^{* *}$ & $2.8 \pm 0.49^{* *}$ \\
\hline 5 & - & $36 \pm 1.4^{*}$ & $13 \pm 0.4^{* *}$ & $1.9 \pm 0.35^{* *}$ & $1.9 \pm 0.08^{* *}$ \\
\hline 10 & - & $28 \pm 0.5^{* *}$ & $10 \pm 2.7^{* *}$ & $1.3 \pm 0.09^{* *}$ & $1.4 \pm 0.03^{* *}$ \\
\hline 15 & - & $20 \pm 0.2^{* *}$ & $8 \pm 0.8^{* *}$ & $---^{z}$ & $---^{z}$ \\
\hline \multicolumn{6}{|c|}{ After 6 weeks of storage } \\
\hline 5 & + & $43 \pm 2.8^{\mathrm{Ns}}$ & $13 \pm 0.3^{* *}$ & $5.1 \pm 0.21^{\mathrm{Ns}}$ & $4.1 \pm 0.25^{\mathrm{Ns}}$ \\
\hline 10 & + & $38 \pm 2.7^{\mathrm{Ns}}$ & $10 \pm 0.5^{* *}$ & $3.0 \pm 0.65^{* *}$ & $2.6 \pm 0.92^{*}$ \\
\hline 15 & + & $26 \pm 2.7^{* * *}$ & $2 \pm 0.4^{* *}$ & $1.4 \pm 0.01^{* *}$ & $2.4 \pm 0.43^{* *}$ \\
\hline 5 & - & $27 \pm 2.9^{* *}$ & $15 \pm 0.6^{* *}$ & $1.5 \pm 0.11^{* *}$ & $1.5 \pm 0.16^{* *}$ \\
\hline 10 & - & $21 \pm 3.2^{* * *}$ & $10 \pm 1.1^{* * *}$ & $1.4 \pm 0.08^{* *}$ & $1.4 \pm 0.06^{* *}$ \\
\hline 15 & - & $20 \pm 0.6^{* *}$ & $6 \pm 0.2^{* * *}$ & $--^{z}$ & $---^{z}$ \\
\hline
\end{tabular}

${ }^{2}$ Chlorophyll fluorescence intensity was not measured for this treatment.

ss, *,**Nonsignificantly or significantly different from those before storage at $P \leq 0.05$ or 0.01 , respectively.

Table 3. Carbon dioxide concentrations inside $\left(\mathrm{C}_{\text {in }}\right)$ and outside $\left(\mathrm{C}_{\text {out }}\right)$ the vessels and net photosynthetic rates per leaf dry weight $\left(\mathrm{P}_{\mathrm{d}}\right)$ measured under culture conditions before storage and after 2 days of culture

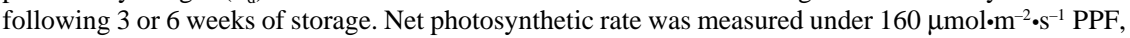
$23 \mathrm{C}$ air temperature, and 3.6 air exchanges per hour for the vessels. Means \pm standard deviations are shown.

\begin{tabular}{|c|c|c|c|c|}
\hline \multicolumn{2}{|c|}{ Treatment } & \multirow{2}{*}{$\begin{array}{c}\mathrm{C}_{\mathrm{in}} \\
\left(\mu \mathrm{mol} \cdot \mathrm{mol}^{-1}\right)\end{array}$} & \multirow{2}{*}{$\begin{array}{c}\mathrm{C}_{\text {out }}^{\mathrm{z}} \\
\left(\mu \mathrm{mol} \cdot \mathrm{mol}^{-1}\right) \\
\end{array}$} & \multirow{2}{*}{$\begin{array}{c}\mathrm{P}_{\mathrm{d}} \\
(\mu \mathrm{mol} \mathrm{CO} / \mathrm{g} \text { dry wt/hour })\end{array}$} \\
\hline Temp $\left({ }^{\circ} \mathrm{C}\right)$ & Light & & & \\
\hline \multicolumn{5}{|c|}{ Before storage } \\
\hline & & $119 \pm 10$ & $444 \pm 19$ & $206 \pm 8.8$ \\
\hline \multicolumn{5}{|c|}{ After 3 weeks of storage } \\
\hline 5 & + & $86 \pm 4$ & $424 \pm 2$ & $178 \pm 2.2^{* * *}$ \\
\hline 10 & + & $102 \pm 10$ & & $189 \pm 5.7$ \\
\hline 15 & + & $177 \pm 27$ & & $204 \pm 22.8^{\mathrm{Ns}}$ \\
\hline 5 & - & $262 \pm 8$ & & $91 \pm 4.8^{* * *}$ \\
\hline 10 & - & $475 \pm 30$ & & $-41 \pm 23.9^{* *}$ \\
\hline 15 & - & $454 \pm 11$ & & $-39 \pm 14.0^{* *}$ \\
\hline \multicolumn{5}{|c|}{ After 6 weeks of storage } \\
\hline 5 & + & $103 \pm 8$ & $404 \pm 2$ & $151 \pm 3.9^{* *}$ \\
\hline 10 & + & $127 \pm 5$ & & $174 \pm 3.1^{* *}$ \\
\hline 15 & + & $467 \pm 12$ & & $-70 \pm 13.6^{* *}$ \\
\hline 5 & - & $417 \pm 4$ & & $-10 \pm 3.2^{* *}$ \\
\hline 10 & - & $432 \pm 24$ & & $-32 \pm 27.7^{* *}$ \\
\hline 15 & - & $411 \pm 8$ & & $-9 \pm 11.2^{* *}$ \\
\hline
\end{tabular}

${ }^{2}$ Carbon dioxide concentrations outside the vessel are common for the treatments.

${ }_{\text {NS, }{ }^{*}, * *}^{*}$ Nonsignificantly or significantly different from those before storage at $P \leq 0.05$ or 0.01 , respectively. 


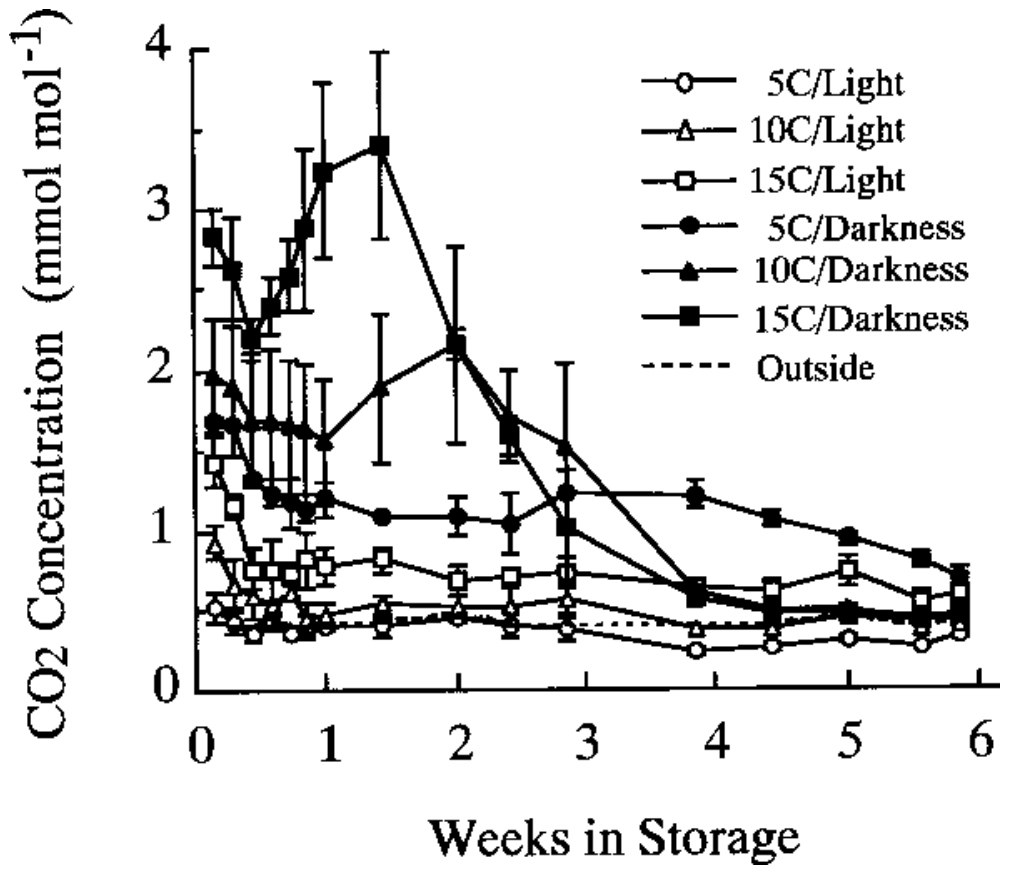

Fig. 1. Carbon dioxide concentrations inside and outside the vessels in storage. Vertical lines represent standard deviations.

light (Fig. 1). The $\mathrm{CO}_{2}$ concentrations inside the vessels were higher at the higher temperatures and were higher in darkness than in light. The $\mathrm{CO}_{2}$ concentrations inside the vessels at 5 or $10 \mathrm{C}$ in light remained almost the same as or even lower than those of the $\mathrm{CO}_{2}$ concentrations outside the vessel $\left(370-500 \mu \mathrm{mol} \cdot \mathrm{mol}^{-1}\right)$. The difference in $\mathrm{CO}_{2}$ concentrations inside and outside the vessel is proportional to the $\mathrm{CO}_{2}$ exchange rate of the plantlets in the vessel. When the $\mathrm{CO}_{2}$ concentrations inside the vessel were lower than outside the vessel, the plantlets had a positive net photosynthetic rate. Therefore, $2 \mu \mathrm{mol} \cdot \mathrm{m}^{-2} \cdot \mathrm{s}^{-1}$ was considered as a PPF close to the light compensation point at 5 to $10 \mathrm{C}$ and around the ambient $\mathrm{CO}_{2}$ concentrations. The total amount of exchanged $\mathrm{CO}_{2}$ for 6 weeks of storage (which is proportional to integrated value of the difference in $\mathrm{CO}_{2}$ concentration inside and outside the vessel), expressed as a positive value when the amount of released $\mathrm{CO}_{2}$ was more than that absorbed, was the highest at $15 \mathrm{C}$ in darkness and lowest at 5C in light (data not shown). This result agrees with changes in dry weight of plantlets during storage. Maintaining the $\mathrm{CO}_{2}$ exchange rate close to zero by illumination at the light compensation point at relatively low temperatures contributes to the preservation of dry weight and photosynthetic and regrowth abilities of the plantlets during storage.

In the vessels stored at 10 or $15 \mathrm{C}$ in darkness, $\mathrm{CO}_{2}$ concentrations increased during days $5-13$, and days $10-20$, respectively, and then decreased. The decrease was due to the decrease in respiration rate, partly resulting from the decrease in dry weight of active parts of the plantlets. The increase was probably due to a climacteric rise in respiration, which is often observed during senescence. The climacteric rise is sometimes associated with ethylene production from senescing organs (Solomos,
1988). Ethylene accumulation is common when plantlets are cultured in airtight vessels (Jackson et al., 1991). In our experiment, accumulation of ethylene $\left(>1 \mu \mathrm{mol} \cdot \mathrm{mol}^{-1}\right)$ was absent throughout storage in all treatments; lower concentrations were not detectable.

Growth of the plantlets after storage. The plantlets stored for 6 weeks at 5 or $10 \mathrm{C}$ in light appeared vigorous after 2 weeks of subsequent culture, while those stored for 3 weeks at 10 or $15 \mathrm{C}$ in darkness or for 6 weeks at 5,10 , or $15 \mathrm{C}$ in darkness or at $15 \mathrm{C}$ in light were dead. The dry weights of plantlets cultured for 2 weeks subsequent to 3 or 6 weeks of storage at 5 or $10 \mathrm{C}$ in light were similar to those of unstored plantlets (Table 4). These also developed new leaves, and their number of leaves was similar to that for unstored plantlets. Plant-
${ }^{2}$ Dashes indicate that plants were dead. storage at $P \leq 0.05$ or 0.01 , respectively. lets stored for 3 weeks at $15 \mathrm{C}$ in light or at $5 \mathrm{C}$ in darkness were damaged, and their older leaves were dead during subsequent culture.

Photosynthetic and regrowth abilities and dry weight of broccoli plantlets cultured photoautotrophically were preserved at 5 and $10 \mathrm{C}$ in conjunction with illumination at as low as 2 $\mu \mathrm{mol} \cdot \mathrm{m}^{-2} \cdot \mathrm{s}^{-1} \mathrm{PPF}$. Marino et al. (1985) found that Prunus rootstocks were better stored in darkness than in light (photoperiod: $16 \mathrm{~h} /$ day) for 10 months at $-3 \mathrm{C}$, while they were better stored in light than in darkness at 4 and $8 \mathrm{C}$. These observations may suggest that proper combinations of temperature, $\mathrm{PPF}, \mathrm{CO}_{2}$ concentrations in the vessel, and sugar concentrations in the culture medium are necessary for better storage. Effects of PPF and temperature were also investigated for the storage of bedding plant plugs (Heins et al., 1992). A PPF of $1 \mu \mathrm{mol} \cdot \mathrm{m}^{-2} \cdot \mathrm{s}^{-1}$ during storage reportedly averted undesirable shoot elongation and decreased mortality of the plants. In our experiment, broccoli was used as model transplants that have low-temperature tolerance. For development of complete storage protocols, the effect of storage on ex vitro performance, including days to set flower, needs to be determined. Controlling the physical environment during low-temperature storage, as related to photosynthetic and regrowth abilities and dry weight change, would be an applicable technique, not only in micropropagation but also in storage of plug seedlings, leafy cuttings, and other leafy plants. Lighting during lowtemperature storage of harvested leafy crops may also be an applicable technique to preserve their quality and dry weight.

\section{Literature Cited}

Arnon, D.I. 1949. Copper enzymes in isolated chloroplasts. Polyphenoloxidase in Beta vulgaris. Plant Physiol. 24:1-15.

Bessembinder, J.J.E., G. Staritsky, and E.A. Zandvoort. 1993. Long-term in vitro storage of Colocasia esculenta under minimal growth conditions. Plant Cell Tissue Organ Cult. 33:121127.

Table 4. Dry weight and number of leaves per plantlet after 2 weeks of subsequent culture without storage (unstored control) and with 3 and 6 weeks of storage. Means with standard deviations were shown.

\begin{tabular}{|c|c|c|c|}
\hline \multicolumn{2}{|c|}{ Treatments } & \multirow{2}{*}{$\begin{array}{c}\text { Dry wt } \\
\text { (mg/plantlet) }\end{array}$} & \multirow{2}{*}{$\begin{array}{c}\text { No. } \\
\text { leaves/plantlet }\end{array}$} \\
\hline Temp $\left({ }^{\circ} \mathrm{C}\right)$ & Light & & \\
\hline \multicolumn{4}{|c|}{ Without storage } \\
\hline \multicolumn{4}{|c|}{ After 3 weeks of storage } \\
\hline 5 & + & $66 \pm 1.1^{\mathrm{Ns}}$ & $7 \pm 0.1^{* *}$ \\
\hline 10 & + & $65 \pm 2.5^{\mathrm{Ns}}$ & $7 \pm 0.2^{*}$ \\
\hline 15 & + & $45 \pm 12.8^{*}$ & $6 \pm 0.8^{\mathrm{Ns}}$ \\
\hline 5 & - & $49 \pm 1.5^{* *}$ & $6 \pm 0.3^{\mathrm{Ns}}$ \\
\hline 10 & - & $--^{2}$ & --- \\
\hline 15 & - & --- & --- \\
\hline \multicolumn{4}{|c|}{ After 6 weeks of storage } \\
\hline 5 & + & $66 \pm 0.9^{\text {Ns }}$ & $7 \pm 0.2^{* *}$ \\
\hline 10 & + & $63 \pm 1.1^{\mathrm{Ns}}$ & $8 \pm 0.2^{* *}$ \\
\hline 15 & + & --- & --- \\
\hline 5 & - & --- & --- \\
\hline 10 & - & --- & --- \\
\hline 15 & - & --- & --- \\
\hline
\end{tabular}

Ns, *, **Nonsignificantly or significantly different from those after 2 weeks of subsequent culture without 


\section{Propagation \& Tissue Culture}

Fujiwara, K., T. Kozai, and I. Watanabe. 1987. Fundamental studies on environments in plant tissue culture vessels. (3) Measurements of carbon dioxide gas concentration in closed vessels containing tissue cultured plantlets and estimates of net photosynthetic rates of the plantlets. J. Agr. Meteorol. 43(1):21-30.

Heins, R.D., N. Lange, and T.F. Wallace, Jr. 1992. Low-temperature storage of bedding-plant plugs, p. 45-64. In: K. Kurata and T. Kozai (eds.). Transplant production systems. Kluwer Academic Publishers, The Netherlands.

Jackson, M.B., A.J. Abbott, A.R. Belcher, K.C. Hall, R. Butler, and J. Cameron. 1991. Ventila- tion in plant tissue cultures and effects of poor aeration of ethylene and carbon dioxide accumulation, oxygen depletion and explant development. Ann. Bot. 67:229-237.

Kozai, T., K. Fujiwara, and I. Watanabe. 1986. Fundamental studies on environments in plant tissue culture vessels. (2) Effects of stoppers and vessels on gas exchange rates between inside and outside of vessels closed with stoppers. J. Agr. Meteorol. 42(2):119-127.

Lichtenthaler, H.K. 1988. In vivo chlorophyll fluorescence as a tool for stress detection in plants, p. 129-142. In: H.K. Lichtenthaler (ed.). Applications of chlorophyll fluorescence in photo- synthesis research, stress physiology, hydrobiology and remote sensing. Kluwer Academic Publishers, The Netherlands.

Marino, G., P. Posati, and F. Sagrati. 1985. Storage of in vitro cultures of Prunus rootstocks. Plant Cell Tissue Organ Cult. 5:73-78.

Murashige, T. and F. Skoog. 1962. A revised medium for rapid growth and bioassays with tobacco tissue cultures. Physiol. Plant. 15:473-497.

Solomos, T. 1988. Respiration in senescing plant organs: Its nature, regulation, and physiological significance, p. 111-145. In: L.D. Nooden and A.C. Leopold (eds.). Senescence and aging in plants. Academic, New York. 